children could receive the language model. Döpk $\mathrm{e}^{[8]}$ demonstrated through the multiple-case-study comparison that parents who persistently use German, (i.e. the minority language in the community) with their children at home are more likely to have their children actively acquiring that language, as compared to parents who tended to resolve into using English (i.e.

\section{The Role of Education in Shaping Parental Language Choices in a Multilingual Society}

\section{Low Hui Min}

School of Educational Studies, University of Science Malaysia, Penang, Minden 11800, Malaysia Email: lowhm@usm.my

Abstract: In a multilingual society, the parents are faced with the need to make language choices when they interact with their young children. Even though language choices in bi-or multilingual families have been vastly reported in the literature on childhood multilingualism, most of these reports reflected the situations involving immigrant or mixedmarriage families who live in a largely monolingual society. In this paper, I argued that the factors that influenced the making the language choices in parents living in a multilingual society are slightly different to those reported in the general literature. From the qualitative investigation with three Malaysian-Chinese families, it was found that the parent language choices were influenced by multiple factors, including the parents' own educational experiences and language repertoires, choices were influenced by multiple factors, including the parents" own educational experiences and language repertoires,
their language attitudes, the language repertoires of the other family members, the family tradition, and most prominently, the educational choices made by the parents for the child. The findings from this investigation added perspectives to understand the extent of complexity involved in the making of language choices by parents in a multilingual society.

Keywords: language choices, multilingual society, Mandarin; English, Penang-Chinese

\section{Introduction}

Unlike monolingual parents, bi-or multilingual parents need to make decision of which language or languages to use with their young child at home ${ }^{[1]}$. The making of language choice could either be a default decision ${ }^{[2]}$ or it could be a process that entails many thoughtful considerations ${ }^{[3]}$. In contexts of childhood multilingualism, language planning at the familial level involves decisions about which language or languages each member in the family is going to speak with their child, and when and where the child will be exposed to these language ${ }^{[4-5]}$. To a certain extent, this notion of language planning at the household level reflects Fishman's ${ }^{[6]}$ sociolinguistic concept, "who speaks what language to whom and when'.

Even though language choices in bi-or multilingual families have been vastly reported in the literature on childhood multilingualism, most of these reports reflected the situations involving immigrant or mixed-marriage families who live in a largely monolingual society ${ }^{[7-10]}$. Many of those reports attributed heritage values, social prestige and socioeconomic reasons as the elements that the bi-or multilingual parents would consider in the making of language choices. Much less is known about how parents in a multilingul society make decisions of which language to use with their young children at known In to to the pares of wa the scenarios in a largely monolingual society, the parents objective of promoting childhood bi-or multilingualism is primarily due to cultural and heritage reasons. Without denying the influences of these two factors in a multilingual society, I will argue in this paper that in a multilingual society, educational choice is another factor that would determine the ways the parents shape their children's early multilingual experiences.

I will use two reports to illustrate these differences. To begin with, the case studies described by Döpk ${ }^{[8]}$ are considered as archetypical representations of mixed-marriage families in a predominantly monolingual society. She investigated twelve German-English mixed-marriage families living in a predominantly English-speaking Australian community. In those families, either the father or the mother in the family was a speaker of German language. Since German was not widely used in the community, the German-speaking parents were almost the only source where their

Copyright 92020 Low Hui Min.
DOI: hthp://doi.org 10.37256 ser



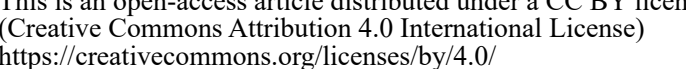

列 to the parents' attribution of cultural and heritage values in learning that language. The similar findings were duplicated in other studies that involved mixed-marriage families in a monolingual society ${ }^{9-10,2}$

However, the reports of case studies in multilingual societies pointed to a slightly different scenario. For example, Kow $^{[13]}$ reported the language choices across the five generations in her own family in Malaysia, where mixed marriages had also occurred. Amongst all the factors like socioeconomic considerations, gender, culture and religion, educational choice emerged as an important factor that steers the direction of language shift and language maintenance in her family. In regards to this, $\mathrm{Kow}^{\left[{ }^{[13]}\right.}$ even perceived education as 'the catalyst for language shift' in her family (p.84). For example, the first generation in her family (Kow's great grandparents) was Thai and Chinese immigrants. Since both Kow's great grandfather and great grandmothers were immigrants, they acquired the pidgin variety of Malay language, known as 'Bahasa Pasar' (it means 'market language' in its literal translation) as a common language in the family and with others in the neighborhood. They also used their respective mother tongues, i.e. Thai and Hainanese (a Chinese variety) with their children. In the subsequent three generations, there was a shift to using pidgin English and then later standard English as the common language at home. This was contributed by the fact that most of the male members in the second and third generations attended schools that used English as the medium of instruction. Belonging to the forth generation in her description, $\mathrm{Kow}^{[18]}$ anticipated that a shift is taking place in her offspring's generation. Even though she introduced English as the first language to her children (i.e. the fifth generation), she arranged them to attend schools that used Endarin as the medium of instruction. This move changed the language repertoire of this generation, to contain a heavie Mandarin as the medium

Kow's ${ }^{[13]}$ findings pointed to a unique aspect in the making of language choice in a multilingual society, in which education is a catalyst of language shift across the generations. To add on to her view, I perceive that education is not only a catalyst of language shift, but also a catalyst of language diversity in a particular generation. Kow' $\mathrm{s}^{[13]}$ case study had also provided evidence for this. For example, $\mathrm{Kow}^{[13]}$ reported that her mother used English with them at home while her father used Cantonese (a Chinese variety). These non-corresponding language choices were driven by their respective educationa experiences, in which her mother had received an English-oriented education while her father had received the Chineseoriented education. This resulted in her competencies in speaking English and Cantonese. Since Kow's ${ }^{[13]}$ description only reflected the scenario in a single family, I speculate that the parents' educational experiences and their corresponding educational choices for their children will correspondingly bring along different language use patterns in different households, given the co-existing of different education systems at one time in a multilingual society, like Malaysia. aimed to explore this in this paper.

In contemporary Malaysia, there are two different main-stream education systems, namely the 'national-type' schools which implement trilingul educetion in English, Malay and a vernacular language (i.e. either Mandarin or Tame')

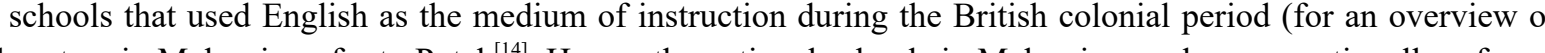
educational system in Malaysia, refer to Puteh ${ }^{[14]}$. Hence, the national schools in Malaysia are also conventionally referred to as either the English-medium schools (mostly referring to those former missionary schools) or the Malay-medium schools, in contrast to the Chinese-medium and the Tamil-medium schools. A brief historical overview of the Malaysia' mainstream education system is presented in Figure 1

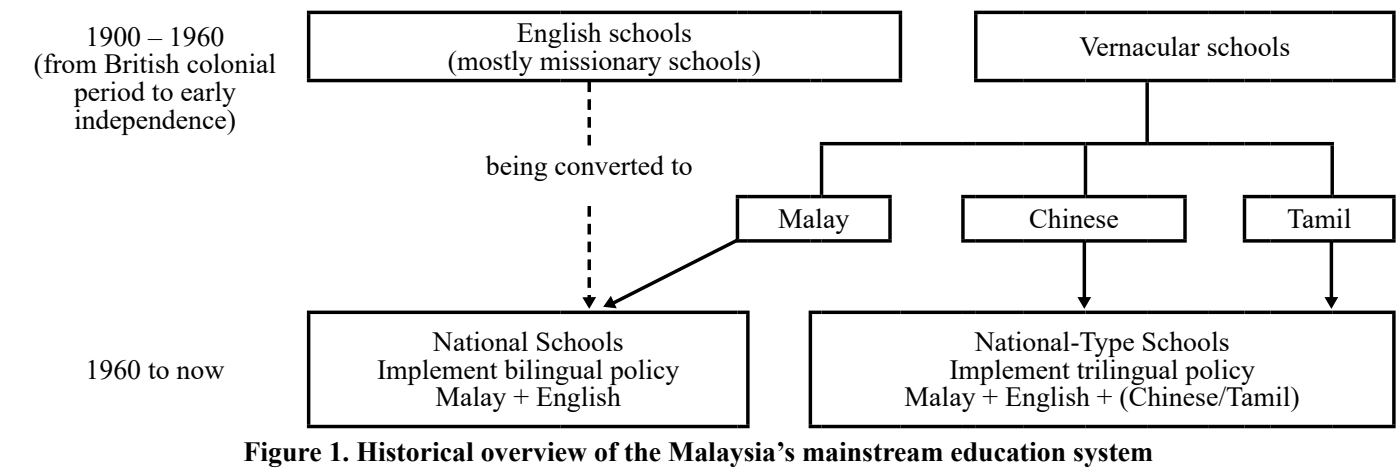


Given the presence of bi-and trilingual education policies in Malaysia, I wish to explore its effects on the parents' language choices in early childhood. To better capture the anticipated diversity, I identified three Malaysian-Chinese families for an in-depth qualitative investigation through semi-structured interviews. Semi-structured interviews consist of several key questions that help to define the areas to be explored ${ }^{[15]}$. This methodology allows the interviewees to elaborate and diverse in order to pursue the ideas that are important to them. The strength of semi-structured interview is its potential

\section{Method}

I chose three Malaysian-Chinese families in my investigation. These three families were recruited for a larger study aimed to investigate childhood multilingualism in Malaysia. In the larger study, I first conducted a community survey involving 100 Chinese mothers in Penang. The community survey was conducted in a private pediatric clinic, visite predominantly by Penang residents from the middle and upper-middle socioeconomic group. The survey findings indicated that $39 \%$ of the mothers felt that their children were hearing predominantly Mandarin at home, $38 \%$ reported an almost balanced distribution of Mandarin and English (23\% slightly Mandarin dominant and 15\% slightly English dominant), $13 \%$ reported English dominance and the remaining 10\% perceived that none of the above categories was appropriate or precise ence (ISO ce: CMN), E code: YUE) are the five major community languages used by the mothers and other adult speakers in the Penang-Chinese community ${ }^{[16]}$.

Informed by the survey data, I selected three children and their families for a longitudinal follow-up. The three children were named as Jason, Isabel and Adam. They were the first-born and the only child in the family during the time of investigation. Jason was reported by his mother to hear predominantly English from both his caregivers. Isabe was reported to hear predominantly Mandarin. Adam was reported to hear mostly English from his mother while mostly Mandarin from his grandmother. All the three children were looked after by their paternal grandmothers when thei mothers were at work. Therefore, in this investigation, I regard the female caregivers, i.e. children's mothers and paternal grandmothers as imposing more influences on the making of language choices than the other male family members at home. This position is in accordance with Gal's $\mathrm{s}^{[17]}$ view that young female language users in a community are relatively more sensitive to the direction of language change as compared to the young men and other people in the community. Other researchers who had the similar view included Harrison and Piete ${ }^{[18]}$, Lyon $^{[19]}$. na Kow ${ }^{[133}$.

The qualitative data reported in this paper were obtained from the semi-structured interviews conducted with the mother and the grandmother in each family to explore the factors contributing to the making of language choices. The interviews were conducted in the beginning of the longitudinal study. The mothers and grandmothers were interviewed individually, during respective home visits. In each interview session, no other adult family members were present. This was to ensure that the interviewees felt comfortable to report their personal opinions during the interviews, without other concerns or considerations. The interviews were audio-recorded and were later transcribed for analysis purposes.

\section{Results}

The interview data will be presented case by case in this section. This is to better portray the associated causal relations of different factors in each case. I will particularly focus on the caregivers' reporting of (1) their language competencies and educational experiences and (2) their aspired educational choices for their children. I also realized from the analysis that the caregivers' perceptions of young children's language learning capacities is potentially another factor that influence their language choices. The scenarios noted in the three families are as follows:

\subsection{Jason's scenario}

Jason is the case-study child who reported to hear predominantly English from people in his family. For Jason, both his father and paternal grandmother received bilingual English and Malay education (i.e. they had attended the Englishmedium or the National schools). English became the natural choice of language in their child rearing practices. There is no report on Jason's paternal grandfather because he had passed away. On the other hand, Jason's mother who attended Chinese-n a dended Chine the use of Mandarin at this stage since Jason's grandmother strongly felt that they shouldo this phase of delopment. Jason's grandmother finmly a

"I say use the word 'beat', and the mother $a h$, Jason EI [: possessive@s:nan] mother $a h$, say 'never mind, let him use two (languages)...'. But this one is complicate to him lah. True oh?" [=ENG+(NAN)]

(Jason's grandmother; time 5:39)

felt that,

“小孩子学语言是没有障碍的。我从来没有想 like 他太小给他太多 language 他不会分。我不, 不认为这样。 因为有些朋友跟我说你给他听太多话他会 blur。我发觉不会喔。我发觉小孩子的学习语言能力是非常好, 他们是可以, anytime 他们都可以懂得说 ... 他们可能会参着来讲, rojak, but 他其实是懂的, 这此是什么, 这些是什么。我没有说 $a$, 没有说只给他讲一种语言, 没有, 没有限制, 就是说, 他要学敦让他学呀。” ” 这些是什么。我份有

$=\mathrm{CMN}+(\mathrm{ENG})$

\%eng: young children do not face with obstacles in language learning. I never felt like because he is too young he will not be able to differentiate (the languages) if I am to impose too many languages to him. I never thought so. Some friends told me that if you let him hear too many languages, he will be blur (= confused). I feel that it is not absolutely. I feel that children have good language learning abilities, they can, and anytime they know how to speak... Maybe they will mix the languages when they speak, rojak[: a-salad-dish@s:zsm], but actually he knows, what are these, these are what. I do not feel it is necessary to only speak to him in one language; no, no restriction, which means, if he wants to learn, let him learn.]

(Jason's mother; time 9:49)

In spite of having this perception, Jason's mother did not appear to intensively use Mandarin and other languages with Jason. As reflected in her reported language use pattern with Jason, she seems to conform to the family's consistent practice of using English as the only dominant language with Jason at this stage. However, she has a plan to enroll Jason in a Chinese-medium school. This plan could be interpreted as her compensation strategy to later reinforce the use of Mandarin with Jason. She explained the reasons behind her educational plan for Jason,

“因为我本身是华校生嘛, 而他爸爸就不是, 他是英校生, 其实他是不大赞成 (\%act: laugh), 我跟他说我
说 “没有啊, 一样的嘛, 学校, 你只要给他外面找到, 找到有英文老师, 给 proper class 给他, 我认为

资 ‘没有啊, 一样的啉, 学校, 你只要给他外面找到, 找到有英文老师, 给 proper class 给他”, 我认为你现在去华校英校都是用马来文来教的 (\%act: laugh) 有什么不一样。…这样近

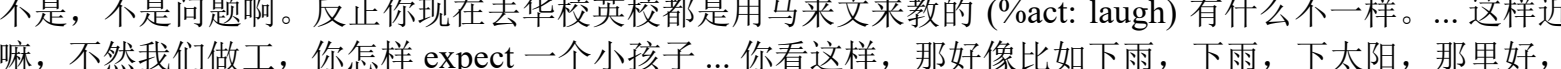

嘛, 不然我们做工, 你怎样 expect 一个小孩子 .... 你看这样, 那好像比如下雨, 下雨,
你给他这样赶来赶去, so, I think (\%act: whisper) 他给我 influence 到。” $\left.{ }^{=}=\mathrm{CMN}+(\mathrm{ENG})\right]$

[\%eng: Because I am a Chinese-school graduate, but his father is not, he is a English-school graduate, actually he does not really agree (\% act: laugh), I spoke to him I said 'not (an issue), (it's) the same, school, as long a you find for him outside, find a English tutor, give him a proper class', I feel that (it is) not, not an issue. Indeed when you now go to Chinese or English schools they also use Malay language to teach (\%act: laugh) where different (= it's the same). .... This (= the school) is near, if not when we were working, how do you expect a young child ... you see, for example when (it's) raining, raining, under the hot sun, where good (= not good) you let him rush here and there like this, so I think (\%act: whisper) he (= Jason's father) has been influenced by me.

(Jason's mother; time 13;02)

In her interview, Jason's mother also revealed that Jason's father initially opposed to the choice of Chinese education In her interview, Jason's mother also revealed that Jason's father initially opposed to the choice of Chinese education
(presumably, this was because it had been the tradition in his family to choose 'English-oriented' education). Jason's
mother finally prevailed since the nearest school to them is a Chinese-medium primary school. Jason's grandmother did not ppose the mother's educational choice for Jason. She felt that it was important to consider convenience in the choice of a school,

"Transport also easy ... convenient lah... just take the umbrella LEI KIE CU KI GUA KAO NEI" [=ENG+NAN] [\%eng: then walk to the outside (school)]

(Jason's grandmother; time 22:28)

This interview data gathered from Jason's mother and grandmother provided an insight on how the factor of education, i.e. the caregivers' past educational experiences and their educational aspirations for the child in the family; together with other factors like their language repertoires and their perceptions of young children's language learning capacities came along in determining their language choices with the child at home. It also emerged from the interview data that for this family, the choice of primarily using one language with the child at that stage was a result of negotiation among the adult family members. Similarly, the anticipating educational option for the child was also a result of negotiation among the adult family members, after they had considered what they feel is the best for the child.

\subsection{Isabel's scenario}

In contrast to Jason's English dominant early language experience at home, Isabel was reported to hear predominantly 
Mandarin from her primary caregivers and the other people in her immediate surroundings. As reported by Isabel's mother, both Isabel's parents had received their early education in Chinese-medium schools, and they communicate between themselves in Mandarin. Isabel's parents speak to each other in Mandarin since Isabel's mother had a reduced proficiency in Hokkien due to her non-Penang origin. Different from other adults in these three families who had Hokkien as their mother tongue, Isabel's mother had Hokchew, another Chinese variety as her mother tongue. On the other hand, Isabel's paternal grandparents communicate between themselves and with Isabel's father in Hokkien. The family as a whole used Mandarin with Isabel.

Isabel's paternal grandmother regarded this language choice to be a natural option for Isabel's mother. However, though Isabel's grandmother was able to converse in Mandarin, she considered her speaking proficiencies in Mandarin as rather limited. Even so, she was supportive of the language choice of Isabel's mother and hence she mainly spoke to Isabel in Mandarin. According to Isabel's grandmother,

"ENG WOOI WO KIA KONG KA YI KONG HOK KIEN WA LEI, YI EI 华语 ... EI O KA BAN lah [=NAN $(\mathrm{CMN})]$

[\%eng: because I worry that if I speak to her in Hokkien, she will learn Mandarin slower.]

She added that:

"ENG WOOI HA MI SU YOU ZAI oh, ENG WOOI YI EI MA SI AI MEH KA TUA CU NEI, SI KONG KUI TIAM ZEN LA MIN NIA. MA EI KA LUA CE LIAO $e h$, WO SIONG KONG LANG KA YI KONG HOK KIEN, KAN ZE SI YI EI 华语 TEH TUI SI KIAM OO LIAO mah...JI TAO KA YI KONG 华语 KA ENG $l o h "$ $[=\mathrm{NAN}+(\mathrm{CMN})]$

[\%eng: because of what do you know (= a stylistic expression), because her mother is only at home at night, only a few hous (before


speak to her (= Isabel) in Hokkien, she will learn less Mandarin... Straight away speak to her in Mandarin it s's
easier.]

(Isabel's grandmother; time 17:05)

Isabel's mother reported a similar perception. She also revealed her worry about using too many languages with young children in early childhood. According to her,

“有些小孩子可以在不同的时候掌握不同的语言, 有些小孩子不能, 他会 confuse。” $[=\mathrm{CMN}+(\mathrm{ENG})]$

[\%eng: some children can learn different languages at different time, some children cannot, he or she will confuse.]

She related this to an incident in her personal experience,
“我有碰过这样的小孩子, 到四岁了他还是不会讲话。

(Isabel's mother; time 14:06)

的就很了, 因为他的妈妈跟他耻 他讲福建话, 他就可以开口讲话了。” [=CMN+(ENG)]

[\%eng: I came across this kind of child, he couldn't speak yet when he was four years old. So his parents became anxious, because his mother spoke to him in English, his father spoke to him in Mandarin, and his grandmother spoke to him in Hokkien, at that time none of the languages he could speak... then when they concentrate on speaking to him in Hokkien, he began to talk.]

(Isabel's mother; time 14:24)

Despite their choice to predominantly use one language with their children at this stage, the mothers of Isabel and Jason did not actually share the same perception towards the use of multiple languages in early childhood. As discussed earlier, Jason's mother was optimistic towards young children having the capacity to learn multiple languages in early childhood. However, she did not translate her thoughts into actions. Her language choice with Jason could be interpreted as being environmentally-driven rather than being her personal intention. In contrast, Isabel's mother did not face the same dilemma. She held the perception that focusing on one language would assist a child to acquire language in early childhood. Her perspective was revealed in her interview:

“英文, 华语两个并行还, 还可以。... 等她比较大一些...会慢慢加强 loh。我们比较 concentrate on 华语, 不要给她 confuse 先 $l o h$ 。我们也担心。” $[=\mathrm{CMN}+(\mathrm{ENG})]$

[\%eng. (speak in) English, Mandarin together is still possible.. Wait until she is older, (we) will slowly reinforce 等 (English) loh. (Now) we concentrate more on Mandarin, (we) do not wish to make her confuse yet loh. We are
also worry.]

(Isabel's mother; time 14:55)
She added that,

“现在常常都会加一些英语给她 liao 了, 再教她两个语言一起 loh. [=CMN]

[\%eng: now (we) frequently add some English (words) for her, after that will teach her two languages together.] (Isabel's mother; time 15:31)

When Isabel's mother and grandmother were asked about educational choices for Isabel, they reported the choice of Chinese education. Isabel's mother commented that,

“因为在华校她可以学会三个语言, 英语, 华语和马来语。去了英校她只会英语和马来语。然后她又是 华人嘛, 她应该要会华语。”

[\% eng: because in the Chinese school, she can learn three languages; English, Mandarin and Malay. (If she) goes to an English school, she will only learn English and Malay. Some more she is a Chinese, she should know Mandarin.]

(Isabel's mother; time 13:22)

Isabel's grandmother added that she regretted her decision to send her daughter (Isabel's paternal aunt) to a National school. According to her,

"KU SI KU CA WO EI CA WA KONG WO HA YI TAK AH MO JE, YI KONG WA HA YI TAK CHU liao. LIE YI EH 华语 BEI HIAO MAH, YI DUI LAI KO MOI WO MOI YI EH PA KONG 'ZHE LEI KIO HA MI HA MI?’ ZHE LEI ZHE LEI MOI liao, MOI KA YI EI PA BAN CAN, YI EI PA KONG ‘WO AI KONG liao, BO LAK BEI KA liao'” [=NAN+(CMN)]

[\%eng: This is because my daughter commented that my decision to let her study in an English school was a wrong move. Then she does not know Mandarin. when she came home she asked me and her father "what is this called (in Mandarin), what is it called?' She asked one word after one word, until her father lost his patience and said 'I am sleepy now, (I have) no strength to teach (you) already'.]

(Isabel's grandmother; time 20:35)

Thus, Isabel's grandmother supported Isabel's mother's decision to enroll Isabel in a Chinese-medium school. In sum, despite the use of a different dominant language with the child in the family, both Isabel's and Jason's families opted for a despite the use of a different dominant language with the child in the family, both Isabel's and Jason's families opted for a
largely sequential method of introducing the multiple languages in early childhood. These two families chose to primarily focus on one language with the child at home, during the early stage of language development. Despite that, they did not purposely exclude all the opportunities where the child could pick up the other languages. Therefore, their approach is arguably more lenient from those minority language parents in a monolingual society who have to deliberately plan and arrange for their children to use the minority language at home (e.g. [8-10]).

Added with the interview findings gathered from Isabel's caregivers, it is again evident that how the factor of education, together with the adults' language repertoires and their perceptions of young children's language learning abilities come together in determining their language choices. It is also noteworthy that despite the fact that both Jason and Isabel shared the same cultural heritages and they were living in the same multilingual society, the early language learning experiences that they had were distinct in the aspect of language types. As suggested by their case-study findings, this distinction was determ this dis experion was dect be considered as te produs educational that there are multiple possibilities in which these factors could interact. The findings implied that in a multilingual society, that there are multiple possibilities in which these factors could interact. The findings implied that
the language choices made by the adult family members at home are not really easily predictable.

\subsection{Adam's scenario}

Next, I examined Adam's sociolinguistic profile. I deduced from the interviews with Adam's mother and grandmother that the language exposure context experienced by Adam was different from those described for Jason and Isabel. As reported by Adam's mother, both she and Adam's father had studied in National-type Chinese-medium schools. They speak to each o grandparents in Hokkien. Additionally, she reported that she and Adam's father speak to Add English interchangeably, while Adam's paternal grandfather and grandmother speak to him predominantly in Mandarin. I noticed during the home visits that Adam's paternal grandmother occasionally incorporated some English vocabulary in the communication which she had with Adam.

In contrast to the scenarios reported for Jason and Isabel, Adam's family constructed Adam's early multilingua experience differently. Both Adam's mother and grandmother, who were his primary caregivers, reportedly use different dominant languages with him, namely English and Mandarin respectively. The opinions related to the importance of 
learning multiple languages given by Adam's mother and grandmother were, by and large, similar to other caregivers in Jason's and Isabel's cases. Similar to other case-study caregivers, Adam's mother and grandmother perceived Mandarin and English as the two most important languages to learn. Adam's mother also pointed to the importance of learning Malay. According to Adam's mother

“um... I suppose 应该是 three, 三种 koa... 会嘛？ Mandarin, English, Malay lah。一点点 ... Hokkien lah... 少 少 $\operatorname{loh} . . . . "[=\mathrm{CMN}+(\mathrm{ENG})]$

[\%eng: um... I suppose (it) should be three, three kinds koa ... right? Mandarin, English (and) Malay lah. A little... Hokkien, a little bit...]

(Adam's mother; time 9:21)

Similar to the opinion given by Adam's mother, Adam's grandmother commented,

“NOU LEI MA 华语 KA A MO, LIE 福建话啊, A NEI loh.” [ $=\mathrm{NAN}+(\mathrm{CMN})]$

[\%eng: Two (languages), Mandarin and English, then Hokkien, like that.]

She added,

(Adam's grandmother; time 5:28

“ENG KAI SI 华语 KA A MO KA YAO KIN hoh? ... TA CHE U YONG TIU EI $m a h . "$ ["NAN+(CMN)]

[\%eng: It should be Chinese and English are more important right hoh? ... (when) study (he) needs to use (these

two languages) mah.]

(Adam's grandmother; time 5:30)

Despite the similarity in their language attitudes, Adam's mother and grandmother seemed to share opposite opinions regarding educational choices for Adam. Adam's mother planned to let Adam receive an English-oriented education. She explained,

“Actually, 我是想送他去 English ed lah. Reason 是我觉得说 $a h .$. Firstly 是我跟他的 father 都不是 from English ed background 的, and then, 我是觉得说如果我们送他去 English ed 的 background, I mean 的 school, 他能 pick up 他的英文 loh. And then, in terms of communication lah, 我们在家我们会教他华语 loh. 我是说 希望他能够 learn proper English lah. $[=\mathrm{CMN}+(\mathrm{ENG})]$

[\%eng: Actually, I wish to send him for English education lah. The reason is I feel ah... Firstly, his father and I are both not from the English education background, and then I feel that if we sent him to (receive) English education, I mean (English) school, he will pick up his English loh. And then, in terms of communication lah, we can teach him Mandarin at home loh. I mean I wish that he could learn proper English lah.]

(Adam's mother; time 10:21)

In contrast, Adam's grandmother felt that,

“ENG KAI SI TAK 华校 KA HO lah hoh? ... A MO SI TOU BEI KAKI 进修 A NEI KUANG loh.

$[=\mathrm{NAN}+(\mathrm{CMN})]$

[\%eng: (It) should be better to study in the Chinese school right? ... English requires self-learning.] (Adam's grandmother; time 6:28)

I inferred from the interviews that Adam's mother and grandmother perceived the importance of Chinese-and Englishriented education differently, and also the modes of learning the two languages, i.e. English and Mandarin differently oriented education differently, and also the modes of learning the two languages, i.e. English and Mandarin differently,
During the course of this investigation, both parties had not come to the point of negotiating the ultimate educational option. This seems to be a reason that had motivated them to use bilingual Mandarin and English with Adam, rather than to adopt a successive way of introducing these two languages, like the caregivers in Jason's and Isabel's cases did. For to adopt a successive way of introducing these two languages, like the caregivers in Jason's and Isabel's cases did. For
this instance, the early bilingual use of Mandarin and English could be interpreted as having the advantage of providing a this instance, the early bilingual use of Mandarin and English could be interpreted as having the advantage of providing a
higher extent of flexibility for subsequent decision making. The finding from Adam's scenario provided another insight on how the educational factor could impact on the caregivers' language choices in a multilingual society.

\section{Conclusion}

As a whole, the qualitative investigation with these three Malaysian-Chinese families provided the evidence that educational factor is a catalyst of language diversity in a multilingual society. As indicated in the caregivers' interview data the motivations for them to use one language over another, such as the choice of either Mandarin or English are influenced by multiple factors, including their own educational experiences and language repertoires, the language repertoires of the other family members, the family tradition, their language attitudes and nevertheless, the educational choices made by the family for the child. On the other hand, the motivation for them to simultaneously or sequentially using more than one language with their child seems to be a consequence of their perceptions towards young children's language learning capacities. Despite the fact that these three families reported in this paper are from the same multilingual society, the adults were making different language choices for their own child at home. As observed in the three families, the adults perceptions on the language-differentiated educational choices are a key factor that contributed to the variety of language choices they made.

Another insight gained from the interview data was on the aspect of language mixing. The interview data provided evidence that language mixing is a common behavior in all the caregivers. As surfaced from the interview data, all caregivers presented with instances of incorporating elements of other languges in their verbalised utterances, even

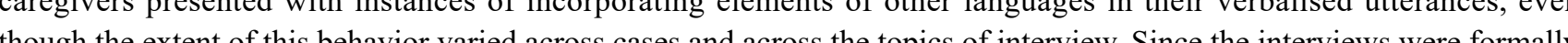
ted to language mixing as a habitual be no evidnce of minimising language mixing in a considerably formal activity insoling researcher, this further suggests that they did not have negative feelings associated with language mixing. This wa consistent with Romaine' $\mathrm{s}^{\mathrm{I}}$ ' speculation of language mixing as an adults' normalised behavior in a multilingual society Therefore, despite the adults claims of favoring the use of one language over another with their young child at home, the extent of language differentiation in their adult-child interactions demands future investigation. This adds on to the extent of complexity involved in the making of language choices by caregivers in a monolingual society

\section{References}

1] De Houwer A, Bornstein MH. Bilingual mothers' language choice in child-directed speech: Continuity and change. Journal of Multilingual and Multicultural Development. 2016; 37(7): 680-693.

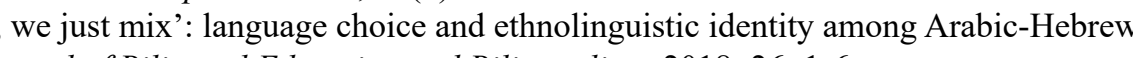
bilinguals in Istis. In

[3] Bezcioglu-Goktolga I, Yagmur K. Home language policy of second-generation Turkish families in the Netherlands.

Chers guide to bilingualism Clevedon: Multilingual Matters. 1995

Cunningham-Andersson U. Growing up with two languages: A practical guide. London: Routledge; 2004.

Fen Publishing; 1985.

One parent one language: An interactional approach. Amsterdam: John Benjamins; 1992

[9] Yamamoto M. Language use in interlingual families: Do different languages make a difference? International Journal of the Sociology of Language. 2008; 189: 133-148.

[10] Jones K, Morris D. Issues of gender and parents' language values in the minority language socialisation of young children in Wales. International Journal of the Sociology of Language. 2009; 195: 117-139.

[11] Romaine S. Bilingualism. 2nd ed. Cornwall: Blackwell Publishing Ltd; 1995.

[12] Takeuchi M. Raising children bilingually through the 'one parent-one language' approach: A case study of Japanese mothers in the Australian context. Bern: Peter Lang: 2006.

[13] Cheng KK. Language shift and language maintenance in mixed marriages: A case study of a Malaysian-Chinese family. International Journal of the Sociology of Language. 2003; 161: 81-90.

[14] Puteh A. Language and nation building: A study of the language medium policy in Malaysia. Petaling Jaya: Strategic Information and Research Development Centre; 2006

[15] Gill P, Stewart K, Treasure E, Chadwick B. Methods of data collection in qualitative research: interviews and focus groups. British Dental Journal. 2008; 204(6): 291-295.

[16] Low HM, Nicholas H, Wales R. A sociolinguistic profile of 100 mothers from middle to upper-middle socio-economic backgrounds in Penang-Chinese community: what languages do they speak at home with their children? Journal of Multilingual and Multicultural Development. 2010; 31(6): 569-584.

[17] Gal S. Peasant men can't get wives: Language change and sex roles in a bilingual community. Language in Society. 1978; 7(1): 1-6

[18] Harrison GJ, Piette AB. Young bilingual children's language selection. Journal of Multilingual \& Multicultural Development. 1980; 1(3): 217-230.

[19] Lyon J. Becoming bilingual: Language acquisition in a bilingual community. Multilingual Matters; 1996. 